\title{
Survey of inappropriate use of magnetic resonance imaging
}

\author{
Heljä Oikarinen • Ari Karttunen • Eija Pääkkö • \\ Osmo Tervonen
}

Received: 24 April 2013 / Revised: 8 July 2013 / Accepted: 10 July 2013 / Published online: 15 August 2013

(C) The Author(s) 2013. This article is published with open access at Springerlink.com

\begin{abstract}
Objective There are concerns that not all costly advanced imaging is appropriate. However, studies about the appropriateness of magnetic resonance imaging (MRI) are sparse. The aim of this study was to review various MRI examinations done at a university hospital to determine whether there is inappropriate use.

Methods Altogether 150 common MRIs (upper abdomen or liver, lumbar spine, knee, head and head of children performed under anaesthesia, 30 each) were reviewed consecutively. The referrals and corresponding patient files were analysed by senior radiologists and the indications of the examinations were compared to the referral criteria.

Results Seven per cent of the examinations were deemed inappropriate. All the MRIs of the head done on children were indicated. One to three examinations in all other subgroups were not indicated. The most common appropriate indications were ambiguous hepatic, pancreatic or adrenal lesions, prolonged lower back pain, suspicion of meniscus rupture, brain malignancy and developmental disorder of a child, respectively.

Conclusions Although the proportion of inappropriate examinations was not high; financial issues and the growing number of patients referred for MRI are of concern. Education and regular use of up-to-date referral guidelines could help to further improve appropriateness.

Main Messages

- Seven per cent of the MRI examinations analysed were inappropriate at a university hospital.

- Everyday practices of a hospital may contribute to the level of appropriateness.

- A survey of indications for previous MRI examinations might be helpful in various institutions.
\end{abstract}

H. Oikarinen $(\varangle) \cdot$ A. Karttunen $\cdot$ E. Pääkkö $\cdot$ O. Tervonen Department of Diagnostic Radiology, Oulu University Hospital, POB 50, 90029 OYS, Oulu, Finland

e-mail: helja.oikarinen@ppshp.fi
Keywords Magnetic resonance imaging - Appropriateness · Quality Assurance $\cdot$ Utilisation management $\cdot$ Referral criteria

\section{Introduction}

The continuous medical and technological progress has led to an increase in medical imaging, including highly technical non-invasive procedures such as magnetic resonance imaging (MRI), computed tomography (CT) and positron emission tomography-CT (PET-CT). There are clear relationships between the availability of imaging units and their use. This has no doubt resulted in benefits to patients. However, it has contributed to a notable increase in health care costs, and suspicions of inappropriate or unnecessary use of imaging have been highlighted. Excessive imaging may also cause additional need for imaging because of false-positive and extra findings. The use of costly advanced imaging should be based on clear guidelines to ensure appropriate use [1-4]. However, there is a wide range of reasons for referrals, including patients' demands. It is also known that there are institutional and regional differences in imaging practice habits $[5,6]$.

There was an 87 per cent increase in the number of MRI examinations performed at our university hospital between 2000 and 2008 (6,491 and 12,150, respectively). We had concerns over financial issues, i.e., the increasing costs of imaging and growing number of patients referred for different MRI examinations. We were also planning to increase our MRI capacity as we expected even more demand for MRI scans in the future, partly because MRI avoids the health risk associated with radiation from a CT examination. We also wanted to know whether there was any need to transfer MRI capacity from one anatomical area to another. Studies about the appropriateness of different MRI examinations are sparse $[5,7]$. Therefore, we decided to analyse indications for various 
MRI examinations done at a university hospital to determine whether there was inappropriate use.

\section{Materials and methods}

Altogether 11,836 MRI examinations were performed at the Department of Diagnostic Radiology of Oulu University Hospital, Oulu, Finland, in 2007. We analysed 150 common MRI examinations: MRI of the upper abdomen or liver (30), lumbar spine referred from the Department of Physical Medicine and Rehabilitation (PMR) (30), knee (30), head (30) and head of children performed under anaesthesia (30). As lower back pain complaints are common and MRI of the lumbar spine is often requested by PMR, we decided to survey that subgroup. We also chose the group of MRI of the head of children done under anaesthesia because there should be good indications for the examination as anaesthesia carries its own risks. Examinations of these groups were extracted from the electronic patient files of our hospital consecutively from the beginning of the year 2007. The evaluation of this study was done in 2009.

Referrals, indications of the examinations, and corresponding patient files were analysed by a senior radiology specialist. Using this information and the referral criteria for imaging recommended by the European Commission (EC) [8], it was decided whether the examination had been indicated. After this, appropriateness of all the MRIs was evaluated by another radiologist trained in neuroradiology (MRIs of the head), abdominal radiology (MRIs of the upper abdomen or the liver) or musculoskeletal radiology (MRIs of the knee or the lumbar spine) by using the data collected. If necessary, consensus was used.

\section{Results}

Seven per cent of all the 150 examinations (10/150) were not appropriate (Table 1). Four out of 30 MRI examinations of the upper abdomen or the liver were not indicated (Table 1). If CT does not reveal any intra-abdominal mass, MRI is not needed. In another patient, suspicion of liver metastases should have been followed by biopsy, not by MRI control. Additionally, CT would be able to show any abnormalities associated with a liver calcification, and the calcification is usually not visible on MRI. A patient with mild upper abdominal pain and without any suspicious symptoms or signs would not have needed MRI. The major indications for appropriate examinations were unclear lesions or status of the liver, pancreas or adrenal gland (20/26 patients) (Table 2).

In the group of MRI examinations of the lumbar spine, 2 out of 30 cases were not appropriate. The problems of the lower legs of one patient were related to a previous assault on the head, not to the lumbar spine. The other patient with mild lower back pain had no specific indications for MRI. Most of the indicated examinations $(25 / 28)$ had been done for prolonged lower back pain.

Three out of 30 MRIs of the knee were considered nonindicated. MRI does not reveal any special findings in painful knees related to previous Osgood-Schlatter disease. Limited
Table 1 The number of analysed MRIs in different subgroups and the number and indications of inappropriate examinations

\begin{tabular}{|c|c|c|c|}
\hline MRI & $\mathrm{n}$ & Not indicated (n) & Indication (n) \\
\hline Upper abdomen & 15 & 2 & $\begin{array}{l}\text { Unclear intra-abdominal expansion at ultrasound, } \\
\text { but CT had been normal (1) } \\
\text { Control of liver metastases seen at MRI (1) }\end{array}$ \\
\hline Liver & 15 & 2 & $\begin{array}{l}\text { A calcification of liver seen at CT (1) } \\
\text { Pain in upper abdomen, ultrasound and laboratory } \\
\text { tests normal (1) }\end{array}$ \\
\hline Lumbar spine & 30 & 2 & $\begin{array}{l}\text { Lower leg dysfunction and pain since assault on the } \\
\text { head years ago (1) } \\
\text { Mild lower back pain, no specific indication (1) }\end{array}$ \\
\hline Knee & 30 & 3 & $\begin{array}{l}\text { Previous Osgood-Schlatter disease, now pain } \\
\text { in the knees (2) } \\
\text { Limited flexion and extension without any trauma (1) }\end{array}$ \\
\hline Head & 30 & 1 & $\begin{array}{l}\text { A terminal patient with defatigation and rapid } \\
\text { deterioration, several CTs lately (1) }\end{array}$ \\
\hline Head, children (anaesthesia) & 30 & 0 & \\
\hline All & 150 & 10 & \\
\hline
\end{tabular}


flexion and extension of the knee were the only information concerning the other patient while referring and performing MRI and would not have indicated MRI. The indication for an appropriate examination was suspicion of meniscus rupture in $19 / 27$ cases.
One out of 30 MRI examinations of the head was not appropriate. There was no indication for MRI after many CT examinations in the case of an elderly terminal patient. The most common appropriate indications were control of a brain tumour or suspicion of brain metastases (9/29). All the MRI

Table 2 The number and indications of appropriate MRI examinations in different subgroups

\begin{tabular}{|c|c|c|c|}
\hline MRI & $\mathrm{n}$ & Indicated (n) & Indication $(\mathrm{n}) *$ \\
\hline Upper abdomen & 15 & 13 & $\begin{array}{l}\text { Unclear hepatic/hepatic hilar/pancreatic or adrenal lesion/status (10) } \\
\text { Unclear pancreatic duct dilatation (1) } \\
\text { Follow-up after laser ablation of a tumour of the kidney (1) } \\
\text { Previous cancer (kidney+GIST**), pain and elevation of tumour marker (1) } \\
\text { Exclusion of residivous pancreatic-cutaneous fistula before operation of lumbar hernia (1) } \\
\text { Leukaemia, control of hepatic fungal infection before stem cell transplant (1) }\end{array}$ \\
\hline Liver & 15 & 13 & $\begin{array}{l}\text { Unclear/follow-up of liver lesions (10) } \\
\text { Suspicion of sclerosing cholangitis (1) } \\
\text { Leukaemia, symptoms of infection (1) } \\
\text { Pain,fever and biliary stasis at ultrasound after laser ablation of hepatocellular carcinoma (1) }\end{array}$ \\
\hline Lumbar spine & 30 & 28 & $\begin{array}{l}\text { Prolonged lower back pain }(25) \\
\text { Prolonged lower leg symptoms }(2) \\
\text { Postoperative lower back pain (1) }\end{array}$ \\
\hline Knee & 30 & 27 & $\begin{array}{l}\text { Suspicion of meniscus rupture (19) } \\
\text { Suspicion of cartilage lesion (3) } \\
\text { Oedema and opaque synovial fluid (1) } \\
\text { Control of liposarcoma (1), myxoma (1) } \\
\text { Suspicion of a loose body (1), detached biceps muscle (1) } \\
\text { Abnormal bone structure in plain x-ray (1) } \\
\text { Previous meniscus operation, postoperative pain (1) }\end{array}$ \\
\hline Head & 30 & 29 & $\begin{array}{l}\text { Control of brain tumour/suspicion of brain metastases (9) } \\
\text { Unclear unconsciousness ( }+ \text { convulsion) (4) } \\
\text { Headache ( }+ \text { visual symptoms) (3) } \\
\text { Suspicion of demyelinization (2), a cavernoma (1), memory disorder (1), } \\
\quad \text { early Parkinson disease (1), sinus thrombosis (1) } \\
\text { Epidemic nephropathy, a study (1), control of brain trauma, a study (1) } \\
\text { Previous paraplegia, brain contusion, now weakness of upper arms (1) } \\
\text { Screening of aneurysm (1) } \\
\text { Control of traumatic bleeding (1) } \\
\text { Control of a previous finding (1) } \\
\text { [One MRI done in error (1)] }\end{array}$ \\
\hline Head, children (anaesthesia) & 30 & 30 & $\begin{array}{l}\text { Developmental disorder (9) } \\
\text { Control of a previous finding (4) } \\
\text { Headache/nocturnal nausea (4) } \\
\text { Seizure of absence (4) } \\
\text { Excessive growth of the head (2) } \\
\text { Leukaemia, planned stem cell transplant (2) } \\
\text { Visual symptoms/stasis papillae (2) } \\
\text { Previous head trauma, acute symptoms of the limbs (1) } \\
\text { Leukaemia, acute brain-based symptoms (1) } \\
\text { Premature infant with intracerebral haematomas, later stiffness of the limbs (1) } \\
\text { Osteopetrosis, status of cranial nerves (1) } \\
\text { Control of brain tumour (1) } \\
\text { Fracture of the skull vault, liquor leakage from the ear (1) }\end{array}$ \\
\hline All & 150 & 140 & \\
\hline
\end{tabular}

* Some patients had more than one symptom/indication

**GIST, gastrointestinal stromal tumour 
examinations of the head performed in children under anaesthesia were indicated. The major indication for MRI was a developmental disorder (9/30).

\section{Discussion}

Appropriate use of both MRI and CT is very important both medically and economically. There are suspicions of various forces influencing overutilisation in many countries, such as financial incentives, self-referrals and defensive medicine [1, 5]. These are probably not major problems in Finland, but we do have concerns about duplicate imaging studies and patient expectations. Institutional and regional variations in imaging patterns and practices may affect appropriateness as well $[5,6]$.

Seven per cent of the MRI examinations analysed in our study were inappropriate. In another study of 3,367 hospitals, the use of outpatient imaging varied widely, possibly indicating overuse. Low imaging volume, a rural setting, for-profit ownership and non-teaching hospitals were more likely to report the highest use. Lack of details about patients' clinical data was reported to be one of the limitations of the study [6]. Another report concerning outpatient CT and MRI scans revealed a 70-fold difference between hospitals in the frequency of scans ordered for a specific indication [9]. There was also a study about outpatient MRIs at a university hospital referred by primary care physicians. It revealed 23 per cent of the 175 examinations to be inappropriate. Most of the inappropriate examinations were in the group of shoulder and lumbar spine MRIs [5]. In another study, referrals for MRI examinations from various hospitals and clinics performing MRI in the area of Stockholm, Sweden, were surveyed. Nine per cent of the MRIs were deemed inappropriate [7].

Our study is an audit from a university hospital. We analysed both the referrals and the corresponding patient files in order to have the same information as the referring physician had while requesting the MRI. In our hospital, MRI examinations are mostly requested by specialists or residents from different departments or outpatient clinics of the hospital itself. Each referral for MRI is also checked by a radiologist before the actual examination in the context of planning the protocol, and the corresponding clinical patient files can usually be evaluated if necessary. At this point, clinicians may be guided and inappropriate referrals may be returned, but these referrals have not been registered. These practices may have contributed partly to the relatively low level of inappropriate examinations.

There are also reports of variable levels of justification of CT scans [10-13]. Our previous study revealed 30 per cent of unjustified CT examinations in young patients [14]. The interventions introduced in 2006 after that study-e.g., distribution of referral guidelines recommended by the $\mathrm{EC}$ and education on indications of different examinations - may also have contributed to the results of the present study. The experience and training of the physicians on the appropriate use of imaging are important ways to improve appropriateness [15]. The referral criteria recommended by the EC have been accepted in Finland and have been translated into Finnish. They were in use in 2007.

According to one study, referring physicians perceive the usefulness of high-cost diagnostic imaging to be lower in unexplained complaints compared to specific diseases [16]. Most of our patients with appropriate examinations seemed to have clear indications for the examinations. MRI is a relatively new method, with rapid advances in technology, and it is used for a growing group of diseases and conditions. We realise that in addition to local habits, resources may be variable. Nevertheless, it would be essential to have clearly specified criteria for the everyday use of MRI for both referring practitioners and radiologists. It would also be important to study the appropriateness of MRI examinations in different kinds of hospitals and clinics. It might reveal the actual level of inappropriate examinations and the variable good or problematic practices that may impact appropriateness.

There are weaknesses in the present study. It is a survey from only one university hospital. We also included only five different types of MRIs in the study and the number of patients in each group is not very high. We did not measure the impact of the referral habits of the requesting physicians or the admission habits of the radiologists separately, either.

In conclusion, seven per cent of the MRI examinations analysed were inappropriate at a university hospital. Although the number was not high, financial issues and the growing number of patients referred for MRI are of concern. Education and regular use of up-to-date referral guidelines by the referring practitioners and the staff of the department of radiology could help to further improve appropriateness.

Conflict of interest The authors declare no conflicts of interest. No funding was received for this work.

Open Access This article is distributed under the terms of the Creative Commons Attribution License which permits any use, distribution, and reproduction in any medium, provided the original author(s) and the source are credited.

\section{References}

1. Hendee WR, Becker GJ, Borgstede JP et al (2010) Addressing overutilization in medical imaging. Radiology 257:240-245

2. Rowan K (2008) Rising costs of medical imaging spur debate. J Natl Cancer Inst 100:1665-1667

3. Baker LC, Atlas SW, Afendulls CC (2008) Expanded use of imaging technology and the challenge of measuring value. Health Aff $27: 1467-1478$ 
4. Mitchell JM (2008) Utilization trends for advanced imaging procedures: evidence from individuals with private insurance coverage in California. Med Care 46:460-466

5. Lehnert BE, Bree RL (2010) Analysis of appropriateness of outpatient $\mathrm{CT}$ and MRI referred from primary care clinics at an academic medical center: How critical is the need for improved decision support? J Am Coll Radiol 7:192-197

6. Mathias JS, Feinglass J, Baker DW (2012) Variations in US hospital performance on imaging-use measures. Med Care 50:808-814

7. Jorulf H, Isberg B, Palmqvist Y, Flodmark O, Zachrisson L, Svahn U (2006) Fokusrapport - Kartläggning av Magnetisk Resonanstomografi. Medicinskt programarbete. Stockholms läns landsting (in Swedish) http://www.produktionssamordning.se/Global/Vardsamordning/ Dokument/Publikationer/Fokusrapporter/FR_Kart1\%C3\%A4ggning_ av_magnetisk_resonanstomografi.pdf

8. Radiation Protection 118. Referral guidelines for imaging (2001) Office for Official Publications of the European Communities, Luxembourg http://ec.europa.eu/energy/nuclear/radioprotection/ publication/doc/118_en.pdf

9. You JJ, Purdy I, Rothwell DM, Przybysz R, Fang J, Laupacis A (2008) Indications for and results of outpatient computed tomography and magnetic resonance imaging in Ontario. Can Assoc Radiol J 59:135-143
10. Almén A, Leitz W, Richter S (2009) National survey on justification of CT-examinations in Sweden. Swedish Radiation Safety Authority:03 http://www.stralsakerhetsmyndigheten.se/Global/Publikationer/ Rapport/Stralskydd/2009/SSM-Rapport-2009-03.pdf

11. Clarke JC, Cranley K, Kelly BE, Bell K, Smith PHS (2001) Provision of MRI can significantly reduce CT collective dose. $\mathrm{Br}$ J Radiol 74:926-931

12. Naik KS, Ness LM, Bowker AMB, Robinson PJA (1996) Is computed tomography of the body overused? An audit of 2068 attendances in a large acute hospital. Br J Radiol 69:126-131

13. Triantopoulou C, Tsalafoutas I, Maniatis P et al (2005) Analysis of radiological examination request forms in conjunction with justification of x-ray exposures. Eur J Radiol 53:306-311

14. Oikarinen H, Meriläinen S, Pääkkö E, Karttunen A, Nieminen MT, Tervonen O (2009) Unjustified CT examinations in young patients. Eur Radiol 19:1161-1165

15. Levy G, Blachar A, Goldstein L et al (2006) Nonradiologist utilization of American College of Radiology Appropriateness Criterias in a preauthorization center for MRI requests: applicability and effects. AJR Am J Roentgenol 187:855-858

16. Schneider A, Rosemann T, Wensing M, Szecsenyi J (2005) Physicians perceived usefulness of high-cost diagnostic imaging studies: results of a referral study in a German medical quality network. BMC Fam Pract 6:22 